Reprod. Nutr. Dévelop., 1987, 27 (1 B), 239-240.

\title{
Les produits de dégradation de la cellulose par les cellulases de Bacteroides succinogenes, bactérie cellulolytique du rumen
}

Geneviève GAUDET

Laboratoire de Microbiologie,

I.N.R.A. Theix, 63122 Ceyrat, France.

Summary. When grown on cellobiose, Bacteroides succinogenes released enzymes in the medium. These enzymes hydrolyzed cellulose into cellodextrins. Periplasmic enzymes degraded cellulose into glucose and cellobiose. When $B$. succinogenes was grown on filter paper, the enzymes that were released in the medium degraded cellulose into a mixture of sugars such as glucose, cellobiose and cellodextrins.

Bacteroides succinogenes est l'une des espèces bactériennes prépondérantes du rumen. Cultivée avec de la cellulose comme seule source de carbone elle libère des endo et exoglucanases dans le milieu, ainsi qu'une cellobiase très sensible à l'oxygène (Schellhorn et Forsberg, 1984 ; Gaudet, 1983 ; Forsberg et Groleau, 1982).

Le but de notre travail est de caractériser les enzymes cellulasiques présents dans le milieu et dans les compartiments bactériens : I'espace périplasmique et les corps bactériens résiduaires représentés par l'ensemble des membranes et le cytoplasme.

Matériel et méthodes. B. succinogenes est cultivé sur le milieu de Bryant et Burkey (1953) à $37^{\circ} \mathrm{C}$ pendant $20 \mathrm{~h}$ lorsque la seule source de carbone est du cellobiose $(2 \mathrm{~g} / \mathrm{l})$ et pendant 3 à 5 jours en présence de papier filtre $(3 \mathrm{~g} / \mathrm{l})$.

Les enzymes extracellulaires sont obtenues par précipitation au sulfate d'ammonium entre 20 et $80 \%$ de saturation, après élimination des bactéries par centrifugation $(9000 \mathrm{~g}-20 \mathrm{~min})$. Les enzymes périplasmiques des bactéries cultivées sur cellobiose sont extraites soit par des techniques de chocs osmotiques soit par du chloroforme (Ames et al., 1984). Ce qui reste des bactéries après extraction du périplasme est appelé corps bactériens résiduaires.

Les différentes fractions enzymatiques (extracellulaires, périplasmiques et bactériennes) sont incubées sur cellulose Avicel pendant 4 jours dans de l'eau distillée en présence d'azide de sodium. Les sucres produits sont identifiés par chromatographie en couche mince sur gel de silice. L'éluent utilisé a la composition suivante (volumes): n-propanol 7, acétate d'éthyl 3, éthanol 3, pyridine 2, acide acétique 2 , eau 5 . Les sucres sont révélés par vaporisation de thymol $(0,5 \%)$ en solution dans de l'alcool $(95 \%)$ et de l'acide sulfurique $(5 \%)$ puis chauffage $10 \mathrm{~min}$ à $180^{\circ} \mathrm{C}$.

Résultats et discussion. Seules les enzymes périplasmiques (tabl. 1) sont capables d'hydrolyser la cellulose jusqu'au stade glucose et/ou cellobiose, alors que les enzymes extracellulaires ainsi que celles qui restent liées aux structures bactériennes après extraction du périplasme, ne dégradent la cellulose que jusqu'au stade cellodextrines. Les deux groupes enzymatiques ont donc des 
activités complémentaires pour l'utilisation de la cellulose par Bacteroides succinogenes.

TABL. 1. - Produits d'hydrolyse de la cellulose Avicel par les différentes préparations enzymatiques.

\begin{tabular}{|c|c|c|c|c|c|}
\hline \multirow{2}{*}{$\begin{array}{l}\begin{array}{l}\text { Préparations } \\
\text { enzymatiques }\end{array} \\
\begin{array}{l}\text { Produits de la } \\
\text { cellulolyse }\end{array}\end{array}$} & \multicolumn{2}{|c|}{ Surnageant de culture } & \multirow{2}{*}{$\begin{array}{c}\text { Enzymes } \\
\text { périplasmiques }\end{array}$} & \multirow{2}{*}{$\begin{array}{l}\text { Corps } \\
\text { bactériens } \\
\text { résiduaires }\end{array}$} & \multirow{2}{*}{$\begin{array}{c}\text { Corps bactériens } \\
+ \\
\text { enzymes } \\
\text { périplasmiques }\end{array}$} \\
\hline & $\begin{array}{l}\text { sur papier } \\
\text { filtre }\end{array}$ & $\begin{array}{c}\text { sur } \\
\text { cellobiose }\end{array}$ & & & \\
\hline $\begin{array}{l}\text { Cellodextrines } \\
\text { (glucose) } \\
3 \leq n \leq 7\end{array}$ & +++ & +++ & traces & +++ & + \\
\hline $\begin{array}{l}\text { Cellobiose } \\
+ \text { glucose }\end{array}$ & + & - & +++ & - & +++ \\
\hline
\end{tabular}

Les enzymes du surnageant de la culture de 3 à 5 jours sur papier filtre ont été libérées au cours de la croissance et par lyse des cellules âgées ; elles incluent donc des enzymes périplasmiques. Sur cellobiose, le surnageant obtenu avant la phase de lyse des bactéries contient principalement des enzymes effectivement libérées dans le milieu.

Les enzymes libérant des cellodextrines sont des endoglucanases; elles sont surtout présentes dans le surnageant de culture et associées aux corps bactériens résiduaires. Les enzymes qui produisent du glucose et/ou du cellobiose sont des exoglucanases. Elles sont seulement présentes dans l'espace périplasmique et sont retrouvées dans le milieu lors de culture sur papier filtre.

Au cours de l'extraction des enzymes périplasmiques, des protéines liées à la membrane externe sont également extraites, les exoglucanases peuvent donc être soit périplasmiques, soit liées à la membrane externe. Les endoglucanases vraisemblablement responsables de l'attaque primaire de la cellulose, sont moins fortement liées aux bactéries puisqu'on en retrouve sous forme libre dans le milieu.

Ames G. F. L., Prody C., Kustu S., 1984. J. Bacteriol., 160, 1181-1183.

Bryant M. P., Burkey L. A., 1953. J. Dairy Sci., 36, 205-217.

Forsberg C. W., Groleau D., 1982. Can. J. Microbiol., 28, 144-148.

Gaudet G., 1983. Ann. Microbiol. (Inst. pasteur), 134, 111-114.

Schellhorn H. E., Forsberg C. W., 1984. Can. J. Microbiol, 30, 930-937. 